\title{
DYNAMIC MANET ON DEMAND PROTOCOL PADA JARINGAN SENSOR NIRKABEL UNTUK SISTEM MONITORING LAHAN PERTANIAN
}

\author{
Agus Halid ${ }^{1}$, Leonardo O. J. Takumansang ${ }^{2}$, Mohammad Fajar ${ }^{3}$ \\ 19agushalid@kharisma.ac.id, ${ }^{2}$ mgccappucino@gmail.com, ${ }^{3}$ fajar@kharisma.ac.id \\ 1,2,3STMIK Kharisma Makassar
}

\begin{abstract}
Abstrak
Penelitian ini bertujuan untuk menerapkan dan mengevaluasi protokol Dynamic Mobile AdHoc Network (DYMO) pada sistem monitoring lahan pertanian berbasis jaringan sensor nirkabel. Rancangan jaringan terdiri dari node sensor yang ditempatkan secara statik di lahan pertanian dan node router serta gateway sebagai node bergerak yang dibawa oleh petani/mobil pertanian. Hasil evaluasi menunjukkan bahwa protokol DYMO dapat digunakan pada jaringan sensor nirkabel untuk sistem monitoring lahan pertanian. Evaluasi rancangan dan skenario di atas lingkungan simulasi OPNET memperlihatkan kinerja jaringan menggunakan protokol DYMO dapat diterima. Salah satu pengujian memperlihatkan rata-rata delay pengiriman dan penerimaan data sebesar $10,812506 / \mathrm{ms}$, minimal waktu delay end-to-end pengiriman dan penerimaan node sebesar 19,105028/ms, maksimal sebesar 19,643988/ms, dan rata-rata pengiriman dan penerimaan delay end-to-end yaitu $19,377766 / \mathrm{ms}$, nilai rata-rata throughput sebesar $46.651 \mathrm{bits} / \mathrm{sec}$. Selain itu, evaluasi awal prototip node sensor berbasis XBee pada jarak 120 meter menunjukkan kinerja jaringan seperti kehilangan paket (packet loss) dan kekuatan sinyal yang dapat diterima.
\end{abstract}

Kata kunci: DYMO Protocol, Monitoring Pertanian, Jaringan Sensor, OPNET, XBee

\section{Pendahuluan}

Jaringan Sensor Nirkabel merupakan salah satu teknologi pengindraan yang berkembang pesat dan mendapat banyak perhatian dari para peneliti dan ahli diberbagai bidang ilmu pengetahuan. Kemudahan dalam perawatan dan biaya pengadaan yang lebih murah dibandingkan teknologi lain, menjadikan teknologi jaringan sensor nirkabel sebagai salah satu pilihan yang banyak diminati dalam mengembangkan sistem-sistem pemantau cerdas diberbagai bidang seperti teknologi pendukung smart city, sistem pemantauan lingkungan, sistem monitoring lahan pertanian dan perkebunan, dan sistem pemantauan kondisi gedung atau jembatan[1]. Jaringan sensor nirkabel terdiri dari sejumlah perangkat yang disebut node sensor yang disebar di suatu lokasi, node sensor ini selanjutnya melakukan pengindraan lingkungan sekitarnya atau objek tertentu, berkomunikasi dengan node lain dalam jaringan sebagai upaya pengiriman atau pengumpulan data hasil pengindraan ke node pengumpul.

Salah satu aspek penting di jaringan sensor nirkabel yaitu protokol komunikasi data yang mengatur bagaimana pesan atau data dikirim dari satu node ke node lain yang sering disebut sebagai routing. Mekanisme routing ini berdampak pada kinerja sistem jaringan sensor nirkabel secara keseluruhan seperti waktu tunda dan kehilangan data pada saat proses komunikasi berlangsung, hingga konsumsi energi jaringan sensor atau masa aktif jaringan sensor [2][3][4]. Sehingga pemilihan atau pemakaian protokol komunikasi dalam jaringan sensor tentunya perlu dipertimbangkan secara cermat. Selain itu lahan pertanian yang umumnya berada jauh dari infrastruktur energi (listrik) dan komunikasi menjadikan pengembang teknologi jaringan sensor dan ahli pertanian perlu membuat desain sistem jaringan sensor yang sesuai dengan kondisi tersebut. Olehnya itu, penelitian ini bertujuan untuk menerapkan dan mengevaluasi protokol Dynamic Mobile Ad-Hoc Network (DYMO) pada jaringan sensor nirkabel dengan merancang sejumlah node yang memiliki kemampuan mobile (bergerak) untuk proses pengumpulan data kondisi lahan pertanian. Pemilihan protokol DYMO dengan sejumlah pertimbangan yaitu memiliki kinerja yang cukup baik dengan kemampuan pembentukan, organisasi dan pengaturan jaringan secara mandiri [5].

\section{Metode}

\subsection{Jaringan Sensor di Pertanian}

Di bidang pertanian, jaringan sensor telah diaplikasikan dalam berbagai bentuk seperti: Monitoring lingkungan, termasuk monitoring cuaca dan pemetaan, pengumpulan data spasial untuk mendukung presisi pertanian, presisi irigasi dan penyedia data ke petani, kendali green house dan 
pakan ternak [6][7][8]. Node pada jaringan sensor di bidang pertanian umumnya dilengkapi dengan sejumlah peralatan sensor untuk mengumpulkan data temperatur dan kelembaban udara, kelembaban tanah, $\mathrm{Ph}$, intensitas cahaya matahari, dan kelembaban daun pada tanaman [9]. Dalam penelitian sebelumnya, peneliti telah mengembangkan prototip node sensor untuk memantau kondisi lahan pertanian seperti yang diperlihatkan pada Gambar 1. Prototip dikembangkan berbasis platform Arduino, modul komunikasi XBee dan Nrf24I01, serta baterai sebagai sumber energinya. Node sensor yang dikembangkan dapat melakukan pengindraan temperatur, kelembaban udara, kelembaban tanah dan $\mathrm{pH}$, kemudian mengirim data hasil pengindraan secara berkala ke node pengumpul (sink).

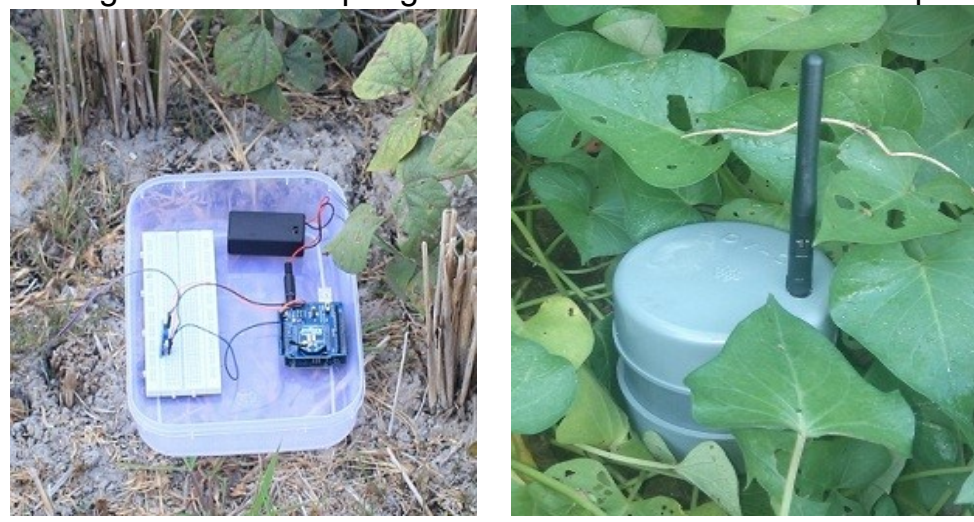

Gambar 1. Prototip node sensor di lahan pertanian

\subsection{Dynamic Mobile Ad-Hoc Network On-Demand (DYMO) Protocol}

Mobile Ad-hoc Network Protocol (MANET) merupakan kumpulan node mobile wireless yang dinamis, membentuk jaringan sementara tanpa menggunakan infrastruktur jaringan yang ada atau tidak bergantung pada administrasi terpusat [10]. Menurut studi dalam [11], protokol DYMO berfungsi untuk menyelenggarakan komunikasi antar node di jaringan secara dinamis tanpa adanya infrastruktur terlebih dahulu (seperti akses point), reaktif, multihop, pengolahan data yang menggunakan sumber daya yang rendah baik memori maupun sumber daya jaringan. Semua node di jaringan MANET memungkinkan melakukan operasi komunikasi secara multi hop karena jangkauan jaringan nirkabel yang terbatas, sehingga terkadang node sumber dan node tujuan tidak datang secara bersamaan pada jaringan, meskipun demikian data dapat terkirim dari node sumber ke node tujuan. Karena topologi jaringan dapat terus berubah (dinamis), maka persoalan pengiriman (routing) paket antara setiap pasangan node menjadi tantangan. Protokol DYMO merupakan turunan dari protokol AODV yang dimodifikasi.

Rute-rute pada jaringan DYMO ditentukan secara unicast dimana node yang melakukan permintaan (request), pada suatu node yang dituju, dan node yang menerima permintaan tersebut, mengirimkan kembali paket data kepada node yang melakukan permintaan. Dalam protokol DYMO, pengiriman dan permintaan data disebut RREQ (route request), sedangkan respon permintaan disebut RREP (route reply). Kualitas pengiriman data dapat dijamin, karena setiap kegagalan pengiriman dapat diketahui oleh pengirim, sehingga pengiriman yang gagal diulang kembali sampai ke node tujuan, kegagalan pengiriman disebut RERR (route error). Skema RERR dapat dilihat pada Gambar 2.

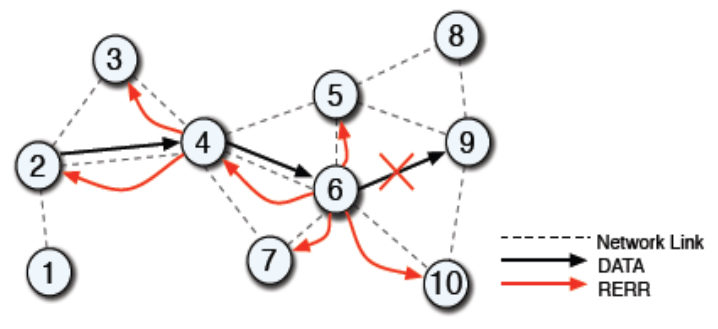

Gambar 2. Proses Penentuan Rute DYMO Protocol [12]

\subsection{Rancangan Pemanfaatan protokol DYMO}

Lahan pertanian yang ditinjau dalam penelitian ini merupakan lahan sawah-padi yang berlokasi di kecamatan Bajeng, Kabupaten Gowa Sulawesi Selatan. Terdapat dua belas petak sawah dan sebuah kanal sebagai sumber air irigasi. Setiap petak sawah memiliki luas $\pm 70 \mathrm{~m} \times 60 \mathrm{~m}$. Dalam 
skema rancangan diberikan inisial lahan $A, B, C, D, E, F, G, H, I, J, K$, dan $L$ seperti yang disajikan pada gambar 3 .

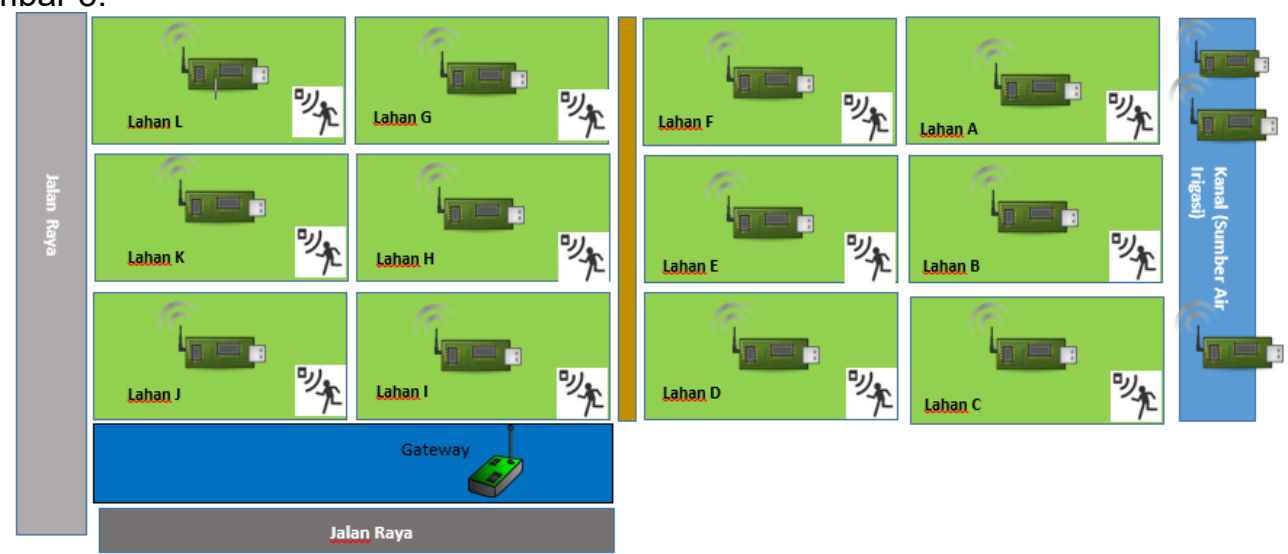

Gambar 3. Arsitektur Rancangan Protokol DYMO untuk Monitoring Lahan Pertanian

Masing-masing lahan dirancang memiliki satu node sensor yang dipasang secara statis (bukan node yang bergerak) bertugas melakukan pengindraan lahan persawahan berupa temperatur, kelembaban udara, intensitas cahaya matahari, dan kelembaban tanah dan mengirim datanya ke gateway. Pada sumber air di kanal dirancang tiga sensor untuk ditempatkan guna mengukur ketinggian air. Sebuah gateway untuk menerima data pengindraan dan meneruskannya ke jaringan lain. Adapun untuk skenario sebagai node bergerak (Mobile Node) pada rancangan ini, adalah node yang akan dibawah oleh petani atau kenderaan pertanian yang mengelilingi masing-masing lahan pertanian, tujuan dari node bergerak yang dibawah oleh petani yaitu sebagai perantara (router) antara node sensor dan gateway. Selain itu dalam skema rancangan ini digunakan satu node gateway yang bertugas untuk melakukan permintaan (request) terhadap node sensor yang berada pada setiap lahan persawahan termasuk node yang ditempatkan di sumber irigasi (kanal).

\section{Hasil dan Pembahasan}

Pada bagian ini penulis menyajikan proses evaluasi, konfigurasi dan hasil evaluasi pemanfaatan protocol DYMO

A. Evaluasi diatas OPNET Modeler

Evaluasi rancangan dilakukan menggunakan software OPNET Modeler 14.5. sebanyak tiga kali simulasi dengan durasi waktu yang berbeda. Simulasi pertama dengan durasi 6 jam yang merupakan rata-rata jam kerja petani bekerja disawah dilokasi yang ditinjau, sedangkan durasi waktu simulasi kedua dan ketiga yaitu 10 jam, dan 20 jam dirancang oleh penulis sebagai pembanding untuk melihat performansi kinerja protokol DYMO dengan waktu yang lebih panjang. Modul komunikasi yang digunakan yaitu XBee, disesuaikan dengan modul komunikasi pada sistem monitoring lahan pertanian yang sedang berjalan [9]. Waktu pengindraan node sensor diset ke $0.25 \mathrm{sec}$. Tabel 1 menyajikan konfigurasi node yang digunakan pada OPNET.

Tabel 1 Konfigurasi Node pada OPNET

\begin{tabular}{|c|l|l|c|c|c|c|c|}
\hline \multirow{2}{*}{ No } & \multirow{2}{*}{ Node } & $\begin{array}{c}\text { Zigbee } \\
\text { Type }\end{array}$ & $\begin{array}{c}\text { PAN } \\
\text { ID }\end{array}$ & frequency & Destination & Start Time & $\begin{array}{c}\text { Stop } \\
\text { Time }\end{array}$ \\
\hline 1 & Gateway & $\begin{array}{l}\text { Zigbee } \\
\text { Cordinator }\end{array}$ & 9 & $2.4 \mathrm{Ghz} / 2450 \mathrm{Mhz}$ & No Traffic & $\begin{array}{l}\text { Uniform(Out } \\
\text { come 20, in } \\
\text { Come 21 }\end{array}$ & 10 \\
\hline 2 & $\begin{array}{l}\text { Node } \\
\text { Sink }\end{array}$ & $\begin{array}{l}\text { Zigbee } \\
\text { Station }\end{array}$ & 9 & $2.4 \mathrm{Ghz} / 2450 \mathrm{Mhz}$ & Gateway & $\begin{array}{l}\text { Uniform(Out } \\
\text { come 20, in } \\
\text { Come 21 }\end{array}$ & infinity \\
\hline 3 & $\begin{array}{l}\text { Mobile } \\
\text { node }\end{array}$ & $\begin{array}{l}\text { Zigbee } \\
\text { Router }\end{array}$ & 9 & $2.4 \mathrm{Ghz} / 2450 \mathrm{Mhz}$ & Random & $\begin{array}{l}\text { Uniform(Out } \\
\text { come 20, in } \\
\text { Come 21 }\end{array}$ & Infinity \\
\hline
\end{tabular}

Selain itu, simulasi juga dilakukan dengan melibatkan skenario berikut: 
1. Luas lahan pertanian keseluruhan yang ditinjau sebesar $500 \mathrm{~m} \times 300 \mathrm{~m}$ yang terdiri dari 12 petak masing-masing sebesar $70 \mathrm{~m} \times 60 \mathrm{~m}$. Node sensor ditempatkan ditengah-tengah pada setiap lahan tersebut $(X=35 \mathrm{~m}$, dan $Y=30 \mathrm{~m})$.

2. Gateway (1 Node) berfungsi untuk me-request data dari setiap node sensor.

3. Node sensor (15 Node)

- 12 node sensor untuk mengukur kelembaban tanah.

- 3 node sensor untuk mengukur level air pada kanal sumber air.

4. Mobile node router (12 Node)

- 12 router node sebagai perantara antara gateway dan node sensor

- 12 router memiliki trajectory yang berfungsi untuk menggerakkan node, dalam pengujian ini mobile node dibawa oleh petani dengan pertimbangan setiap mobile node memiliki waktu tempuh 1 jam 50 menit kurang lebih $68 \mathrm{~m}$ sehingga dapat mengelilingi area pertanian.

- Setiap mobile node router ditempatkan pada masing-masing lahan.

Gambar 4 menyajikan skenario yang digunakan menggunakan OPNET.

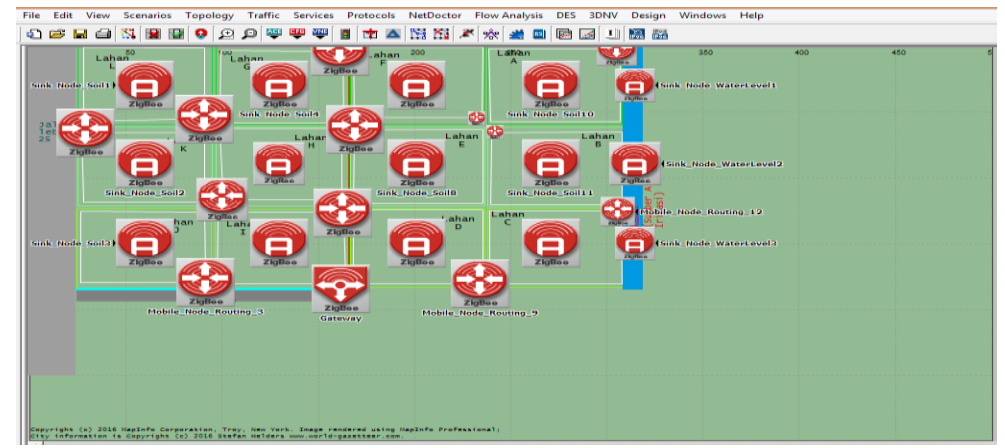

Gambar 4. Skenario Rancangan Simulasi Lahan Pertanian pada OPNET

Pada pengujian pertama didapatkan minimal waktu delay pengiriman dan penerimaan data selama $10,064324 / \mathrm{ms}$, maksimal $10,955233 / \mathrm{ms}$, dan rata-rata delay pengiriman data dan penerimaan data selama $10,812506 / \mathrm{ms}$, minimal waktu delay end-to-end pengiriman dan penerimaan node selama $19,105028 / \mathrm{ms}$, maksimal $19,643988 / \mathrm{ms}$, dan rata-rata pengiriman dan penerimaan delay endto-end selama $19,377766 / \mathrm{ms}$, nilai rata-rata throughput sebesar 46.651 bits/sec. Gambar 5 memperlihatkan salah satu grafik hasil evaluasi pengujian yang dilakukan.

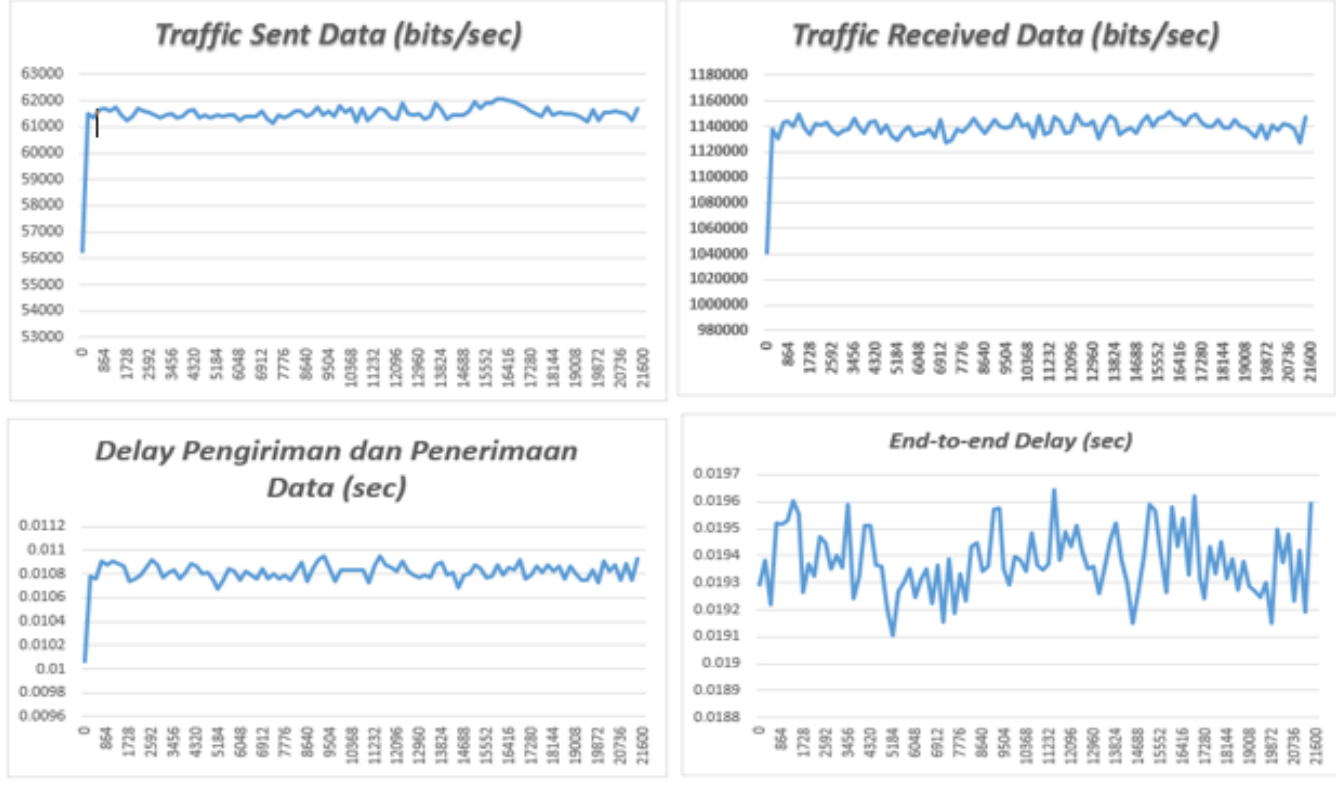


ILKOM Jurnal Ilmiah Volume 9 Nomor 2 Agustus 2017

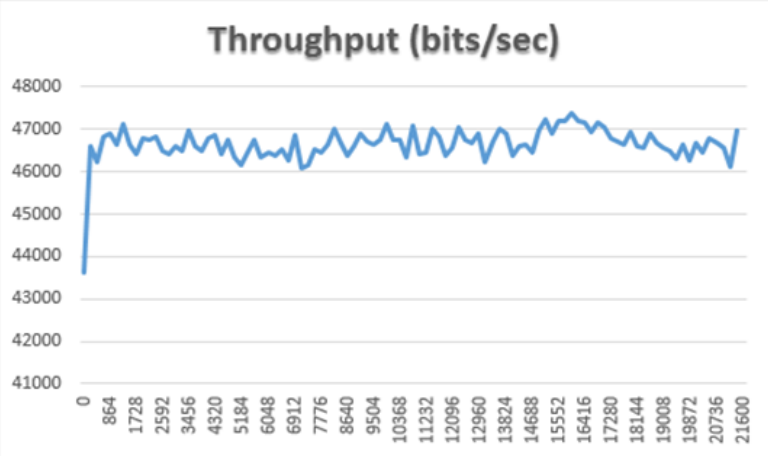

Gambar 5. Grafik Performansi Jaringan pada Pengujian Pertama

Hasil pengujian menggunakan durasi waktu simulasi yang berbeda menampilkan rute pengiriman dan penerimaan data dari gateway menuju ke node sensor dengan jumlah loncatan yang sama, pada node sensor maupun mobile node router terlihat pada Gambar 6.

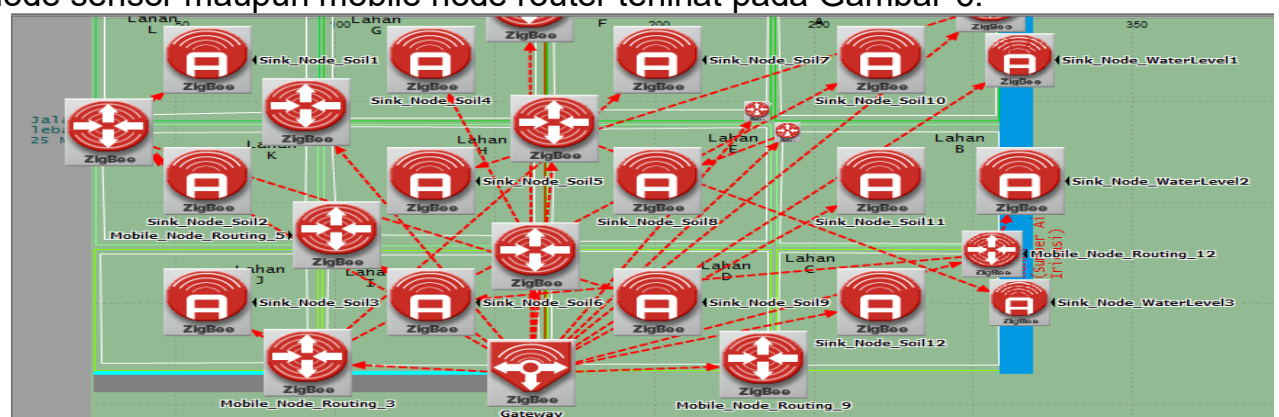

Gambar 6. Lompatan dari Gateway menuju Node Sensor

Dari evaluasi kinerja protokol DYMO untuk sistem monitoring lahan pertanian dengan lama waktu simulasi yang berbeda yaitu 6, 10, dan 20 jam, banyaknya traffic pengiriman dan penerimaan data yang menuju gateway dipengaruhi oleh delay, end-to-end delay dan throughput, semakin kecil waktu delay dan end-to-end delay maka kualitas pengiriman dan penerimaan data tentunya dipandang semakin baik. Olehnya itu, hasil evaluasi kinerja protokol DYMO yang diskenariokan dalam penelitian ini dipandang cukup baik dan dapat diterima.

\section{B. Evaluasi pada Platform XBee}

Pada evaluasi awal ini, 3 node menggunakan modul XBee digunakan untuk mengukur kinerja jaringan: 1 node sebagai node sensor, 1 node sebagai router (mobile node) dan 1 node sebagai koordinator. Node koordinator bertanggungjawab dalam pembentukan dan manajemen jaringan, modul ini digunakan di node sink. Node router berfungsi meneruskan paket dari node sensor ke koordinator. Sedangkan node akhir berfungsi sebagai node pengirim atau penerima informasi di jaringan. Node akhir dipasang pada node sensor. Jaringan dibuat point to point, multihop dan node router diskenariokan sebagai node yang bersifat bergerak (mobile). Jaringan hanya terbentuk apabila node router telah diaktifkan atau memasuki area komunikasi. Tabel 2 menyajikan konfigurasi pada software XCTU yang digunakan untuk node koordinator, pengaturan chanel dan PAN ID jaringan.

Tabel 2 Konfigurasi Node pada Software XCTU

\begin{tabular}{|l|l|l|}
\hline Node & Nama field & Nilai Konfigurasi \\
\hline Coordinator: ZNet 2.5 Coordinator API & PAN ID & 333 \\
\hline & SC Scan Channels & 1FFE (Default) \\
\hline & SD Scan Duration & 3 (Default) \\
\hline & NJ Node Join Time & FF (Default) \\
\hline & SH Serial Number High & 13 A200 (Default) \\
\hline & SH Serial Number Low & 4081 A9B8 (Default) \\
\hline Sensor Node: ZNet 2.5 End/Router API & PAN ID & 333 \\
\hline & DH Destination Address High & 13 A200 \\
\hline & DH Destination Address Low & 4081A9B8 \\
\hline
\end{tabular}


Hasil pengujian jarak 120 Meter memperlihatkan rata-rata kehilangan paket dapat diterima yaitu sebesar $0.6 \%$. Selain itu indikator kekuatan sinyal memperlihatkan kualitas sinyal yang cukup baik berkisar $-50 \mathrm{dBM}$ dan $-75 \mathrm{dBm}$. Gambar 7 memperlihatkan prototip yang digunakan dan hasil pengujian indikator sinyal node sensor menggunakan XBee pada jarak uji $120 \mathrm{~m}$.

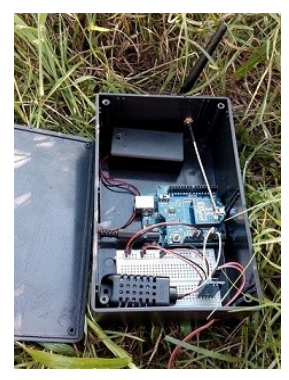

(a) Node sensor XBee

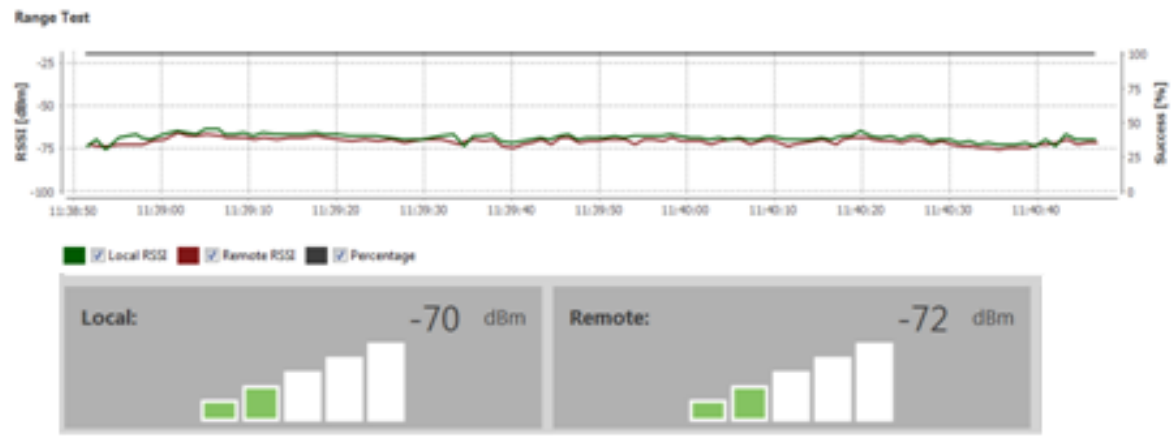

(b) indikator pengujian range XBee

Gambar 7. Prototip Node Sensor Berbasis XBee (a) yang digunakan dalam studi ini dan indikator hasil pengujian range XBee $120 \mathrm{~m}$ (b).

\section{Kesimpulan dan saran}

Penelitian ini memperlihatkan bahwa protokol DYMO dapat digunakan untuk membangun sistem jaringan monitoring lahan pertanian berbasis Mobile Adhoc (MANET). Evaluasi rancangan dan skenario di atas lingkungan simulasi OPNET memperlihatkan kinerja jaringan menggunakan protokol DYMO dapat diterima. Salah satu evaluasi memperlihatkan rata-rata delay pengiriman dan penerimaan data sebesar $10,812506 / \mathrm{ms}$, minimal waktu delay end-to-end pengiriman dan penerimaan node sebesar $19,105028 / \mathrm{ms}$, maksimal sebesar $19,643988 / \mathrm{ms}$, dan rata-rata pengiriman dan penerimaan delay end-to-end yaitu $19,377766 / \mathrm{ms}$, nilai rata-rata throughput sebesar 46.651 bits/sec. Selain itu, evaluasi awal prototip node sensor berbasis XBee pada jarak 120 meter menunjukkan kinerja jaringan seperti kehilangan paket (packet loss) dan kekuatan sinyal yang dapat diterima. Untuk penelitian selanjutnya, dapat difokuskan pada evaluasi protokol DYMO dengan melibatkan beberapa node sensor statis yang berkomunikasi dengan beberapa node router bergerak (mobile) di lahan pertanian, selanjutnya mengukur konsumsi energi setiap node sensor dan router tersebut, sehingga kebutuhan energi jaringan dapat diprediksi.

\section{Ucapan Terima Kasih}

Terima kasih kepada DRPM Kemenristekdikti atas dukungan dana penelitian melalui skema penelitian produk terapan tahun 2017.

\section{Daftar Pustaka}

[1] Kyildiz, Ian F., Vuran, Mehmet Can. 2010. Wireless Sensor Networks. Willey \& Sons.

[2] Al-Karaki, J. N. and Kamal, A. E. 2014. Routing techniques in wireless sensor networks: a survey, IEEE Wireless Communications, Vol. 11. No. 6. pp. 6-28.

[3] Heinzelman, W. R., Chandrakasan, A., Balakrishnan, H. 2000. Energy efficient communication protocol for wireless microsensor networks, Proc. of the 33rd IEEE HICSS, pp. 1-10.

[4] Nasim, M. dan Qaisar, S. 2011. Cooperative Communication for Energy Efficiency in Mobile Wireless Sensor Networks. In: Murgante B., Gervasi O., Iglesias A., Taniar D., Apduhan B.O. (eds) Computational Science and Its Applications - ICCSA 2011. Lecture Notes in Computer Science. Berlin Germany: Springer. vol. 6785.

[5] Fernandes, A., Couceiro, M. S., Portugal, D., Santos, J.,M. dan Rocha, R. P. 2015. Ad hoc communication in teams of mobile robots using zigbee technology. Comput Appl Eng Educ, 23: 733-745. doi:10.1002/cae. 21646

[6] Liu, H., Meng, Z., M. Wang, M. 2009. A Wireless Sensor Network for Crop land Environmental Monitoring, International Conference on Networks Security. Wireless Communications and Trusted Computing. NSWCTC '09. Volume 1. pp: $5-68$.

[7] Riquelme, A.L, Soto, F., Suardiaz, J., Sanchez, P., Iborra, A., dan Vera, J.A. 2009. Wireless Sensor Networks for Precision Horticulture in Southern Spain. Computers and Electronics in Agriculture. Volume 68. Issue 1. pp.25-35. 


\section{ILKOM Jurnal Ilmiah Volume 9 Nomor 2 Agustus 2017}

[8] Chaudhary, D.D., Nayse, S.P., dan Waghmare, L.M. 2011. Application of wireless sensor networks for greenhouse parameter control in precision agriculture. International Journal of Wireless \& Mobile Networks (IJWMN). Vol. 3. No. 1.

[9] Fajar, M., Halid, A., Arfandy, H. dan Munir, A. 2016. Development of A Low Cost Wireless Sensor Network for a Real Time Paddy Field Monitoring System. International Journal of u- and eservice, Science and Technology. Vol. 9. No. 12, pp. 397-406.

[10] Alilou, M., dan Dehghan.t, M. 2007. Upgrading Performance of DSR Routing Protocol in Mobile Ad Hoc Networks. International Journal of Electrical, Computer, Energetic, Electronic and Communication Engineering, Vol. 1, No.5, pp 762-764.

[11] Chakeres, I., dan Perkins, C. 2009. Dynamic MANET On-demand (DYMO) Routing. Mobile Ad hoc Networks Working. IETF. Retrieved April 7, 2016, from http://tools.ietf.org/pdf/draft-ietfmanet-dymo-17.pdf

[12] Johnson, D. B., Maltz, D. A., dan Hu, Y.-C. 2004. The Dynamic Source Routing Protocol (DSR). Rice University, Mellon University. IETF MANET Working Group. Retrieved April 7, 2016, from https://tools.ietf.org/pdf/draft-ietf-manet-dsr-10.pdf 